\title{
Influence of Amphetamines on Plasma Corticosteroid and Growth Hormone Levels in Man
}

\author{
G. M. BESSER,* M.D., B.SC., M.R.C.P. ; P. W. P. BUTLER, $†$ M.B., M.R.C.P. ; J. LANDON, $\ddagger$ M.D. \\ LESLEY REES, $\dagger$ M.B., M.R.C.P.
}

British Medical fournal, 1969, 4, 528-530

\begin{abstract}
Summary : Plasma fluorogenic corticosteroid and immunoreactive growth hormone levels rose significantly after the intravenous administration of methylamphetamine to healthy young men at various times of the day. The rise in corticosteroids was most pronounced in the evening and was accompanied by an increase in circulating levels of immunoreactive corticotrophin. Oral dexamphetamine also resulted in significant rises in plasma corticosteroids but not in growth hormone. These hormonal changes were accompanied by evidence of mild central stimulation. Though they may be part of an associated and non-specific response, it is more likely that they represent specific effects of amphetamines on centres in the hypothalamus or midbrain controlling secretion of corticotrophin and growth hormone releasing factors.
\end{abstract}

\section{Introduction}

The administration of amphetamine and hydroxyamphetamine causes depletion of the ascorbic acid content of the rat adrenal gland and amphetamine increases plasma 17-hydroxycorticosteroid levels in guinea-pigs, effects presumed to be due to stimulation of corticotrophin (A.C.T.H.) secretion (Nasmyth, 1949 ; Ohler and Wakerlin, 1951 ; Naumenko, 1967). Dexamphetamine has been shown to increase the growth hormone content of the rat pituitary (Müller et al., 1967). There have, however, been few reports of the effect of amphetamines on human anterior pituitary function. In a previous study (Butler et al., 1968) it was found that the oral administration of a small dose of dexamphetamine to normal subjects blocked the fall in plasma corticosteroid level normally seen in the evening as part of the nyctohemeral rhythm.

There is considerable evidence, both from neuropharmacological and from behavioural studies, that A.C.T.H. and corticosteroids may directly affect the central nervous system (for a recent review of this subject see Mess and Martini, 1968). Thus central stimulatory effects are frequently observed during A.C.T.H. and corticosteroid therapy, and a significant proportion of patients with endogenous hyperadrenocorticism manifest psychological symptoms. A.C.T.H. has been shown to have an anticonvulsant action in children (Klein and Livingston, 1950), to delay the extinction of avoidance learning (Murphy and Miller, 1955), and to influence sexual behaviour in rabbits (Korányi et al., 1966).

From these observations it appears that on one hand amphetamines increase pituitary-adrenal activity as well as causing central stimulation, while on the other hand adrenocortical overactivity may itself produce central effects. In view of this the present investigation was carried out to assess further the relation between amphetamines, endocrine function, and behavioural and psychomotor changes. Plasma fluorogenic

* Senior Lecturer In Medicine, Medical Professorial Unit.

† Registrar, Medical Professorial Unit.

† Professor of Chemical Pathology.

St. Bartholomew's Hospital, London E.C.1. corticosteroid and immunoreactive A.C.T.H. and growth hormone levels were determined in normal young men after the administration of dexamphetamine and methylamphetamine. Amphetamines cause greater central stimulation when given to fatigued subjects (Weiss and Laties, 1962), and studies were therefore made in the morning and evening.

\section{Volunteers and Methods}

Eight healthy male volunteers aged 19 to 24 were given oral dexamphetamine. They were studied in the non-fasting state. Each was tested after $10 \mathrm{mg}$. of dexamphetamine and again with a placebo at 9.30 a.m. and at 6 p.m. Blood samples were taken for plasma growth hormone and fluorogenic corticosteroid determinations before and 90, 180, and 330 minutes after capsule administration. Psychological tests were performed and the pulse rate was recorded at 30-minute intervals for 3 hours and finally at 320 minutes.

Six healthy male volunteers aged 20 to 28 were given intravenous methylamphetamine. Each was tested with $15 \mathrm{mg}$. of methylamphetamine and again with a placebo at 9 a.m., 6 p.m., and midnight, and with $7.5 \mathrm{mg}$. of methylamphetamine at 9 a.m. and 6 p.m. The subjects were fasted overnight and throughout the 9 a.m. tests, but it was not considered feasible to fast them for the later tests. All tests were performed with an indwelling cannula inserted into a forearm vein at least 30 minutes previously. Blood samples were taken before and $15,30,45$, and 60 minutes after injection for plasma growth hormone and fluorogenic corticosteroid determinations at 9 a.m. and 6 p.m., and for plasma fluorogenic corticosteroids alone at midnight. No psychological tests were made.

Plasma immunoreactive A.C.T.H. and fluorogenic corticosteroid levels were determined in two additional subjects after the intravenous administration of $15 \mathrm{mg}$. of methylamphetamine at 9 a.m.

Allocation of treatment was on a double-blind, cross-over, randomized basis using a Latin square design, with a seven-day interval between tests in each subject. The changes from the initial control values at each time interval were calculated for each individual on the active and placebo treatments. The differences between those changes were analysed, Student's $t$ test being used.

The following psychological tests were performed: the digitsymbol-substitution test described by Kornetsky and Humphries (1958) was used to assess coding ability ; a tapping procedure (Dickens et al., 1965) was employed to study the ability to perform rapid fine movements ; changes in hunger and restlessness were assessed by the technique of Silverstone and Stunkard (1968); and mood was assessed by means of a simple check-list described previously, devised for use with centrally acting drugs (Besser and Steinberg, 1967).

Plasma fluorogenic corticosteroids were measured by the method of Mattingly (1962), and growth hormone and A.C.T.H. by radioimmunoassay techniques (Hunter and Greenwood, 1964 ; Landon and Greenwood, 1968). 


\section{November 1969 Amphetamines and Corticosteroid Levels-Besser et al.}

\section{Results}

\section{Oral Dexamphetamine Studies}

Dexamphetamine produced a significant increase in the number of symptoms describing stimulation of mood as compared with the administration of a placebo $(P<0.05)$. This effect was similar in both the morning and the evening studies. The results of the other psychological tests are shown in Table I. Significant changes were found only with the digitsymbol-substitution test and in the assessment of hunger. The pulse rate was increased significantly (by 13 beats/minute) only at 320 minutes in the morning $(P<0.05)$.

TABLE I.-Psychological Tests. Mean Changes from Baseline Scores

\begin{tabular}{|c|c|c|c|c|c|c|}
\hline \multirow{2}{*}{ Tests } & \multicolumn{3}{|c|}{ a.m. } & \multicolumn{3}{|c|}{ p.m. } \\
\hline & $90 \mathrm{~min}$. & $180 \mathrm{~min}$. & $320 \mathrm{~min}$. & $90 \mathrm{~min}$. & $180 \mathrm{~min}$. & $320 \mathrm{~min}$. \\
\hline $\begin{array}{l}\begin{array}{l}\text { Digit-symbol } \\
\text { substitution } \\
\begin{array}{l}\text { Tapping } \\
\text { Hunger }\end{array} \\
\text { Restlessness }\end{array} \quad \text {.. }\end{array}$ & $\begin{array}{l}+25^{*} \\
+14 \cdot 5 \\
-19 \cdot 1 \\
+7 \cdot 7\end{array}$ & $\begin{array}{l}+1 \cdot 9 \\
+17 \cdot 5 \\
-36 \cdot 3 * \\
+18 \cdot 5\end{array}$ & $\begin{array}{r}+0.3 \\
+15.4 \\
-7.5 \\
+4.5\end{array}$ & $\begin{array}{l}+0.9 \dagger \\
+7.9 \\
-12.0 \\
+14.9\end{array}$ & $\begin{array}{l}+3.0 \ddagger \\
+11.5 \\
-18.6 \\
+22.0\end{array}$ & $\begin{array}{r}+0.4 \\
-1.7 \\
-10.6 \\
+15.0\end{array}$ \\
\hline
\end{tabular}

Those scores which show significant differences between the active and placebo effects are indicated as follows: $* P<0.05,+P<0.01, \neq P<0.001$.

Higher mean plasma fluorogenic corticosteroid levels were found at all times after the oral administration of the drug as compared with the placebo (Fig. 1). These differences were significant at 180 minutes $(P<0.05)$ in the morning and at 90 minutes $(P<0.01)$ and 180 minutes $(P<0.02)$ in the evening. The mean rise was greater in the evening than in the morning, but this difference was not significant. Plasma growth hormone levels were not significantly altered at any time.
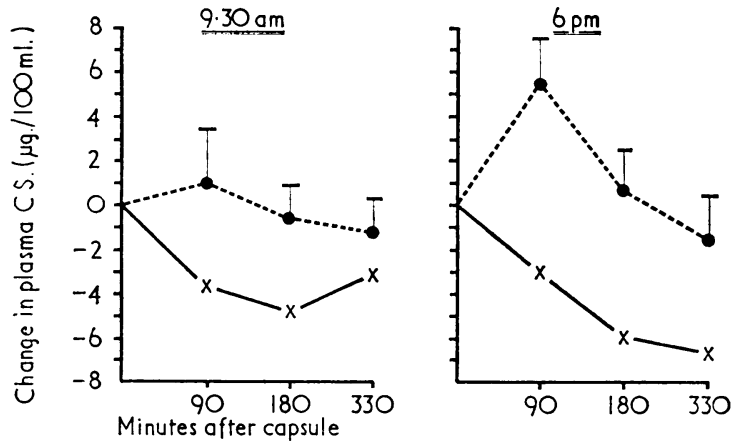

FIG. 1.-Change in plasma fluorogenic corticosteroids (plasma CS.) after $10 \mathrm{mg}$. of oral dexamphetamine $\left.(0-)_{0}\right)$ and a placebo $\left(\times \frac{}{\times}\right)$ given at 9.30 a.m. and 6 p.m. Vertical bars represent 1 S.E. of the difference between means.

\section{Intravenous Methylamphetamine Studies}

The intravenous administration of $7.5 \mathrm{mg}$. and $15 \mathrm{mg}$. of methylamphetamine at 9 a.m. (Fig. 2) caused a significant rise in the mean plasma fluorogenic corticosteroid levels after 30 , 45 , and 60 minutes $(P<0.05)$.

At 6 p.m. the 7.5-mg. dose had no effect, but $15 \mathrm{mg}$. produced a significant rise in plasma corticosteroids at 30 minutes $(\mathbf{P}<0.001)$. The $15-\mathrm{mg}$. dose also produced a significant response 30,45 , and 60 minutes after its midnight injection $(P<0.01)$. Comparison between the responses to the $15-\mathrm{mg}$. dose given at different times of the day (Fig. 2) showed no significant difference between 6 p.m. and midnight, but the maximum rise at both these times was greater $(P<0.001)$ than that obtained at 9 a.m. The mean absolute maximum levels after $15 \mathrm{mg}$. were $22.0 \mu \mathrm{g} . / 100 \mathrm{ml}$. at 9 a.m., $26.3 \mu \mathrm{g} . / 100 \mathrm{ml}$. at 6 p.m., and $19.2 \mu \mathrm{g} . / 100 \mathrm{ml}$. at midnight ; these 9 a.m. and 6 p.m. maxima were not significantly different, but the midnight maximum was less than that at 6 p.m. $(P<0.05)$.
The maximum increments in plasma growth hormone after each dose of methylamphetamine are compared with the placebo response in Table II. There was no significant difference between the morning and evening results, and these were combined.

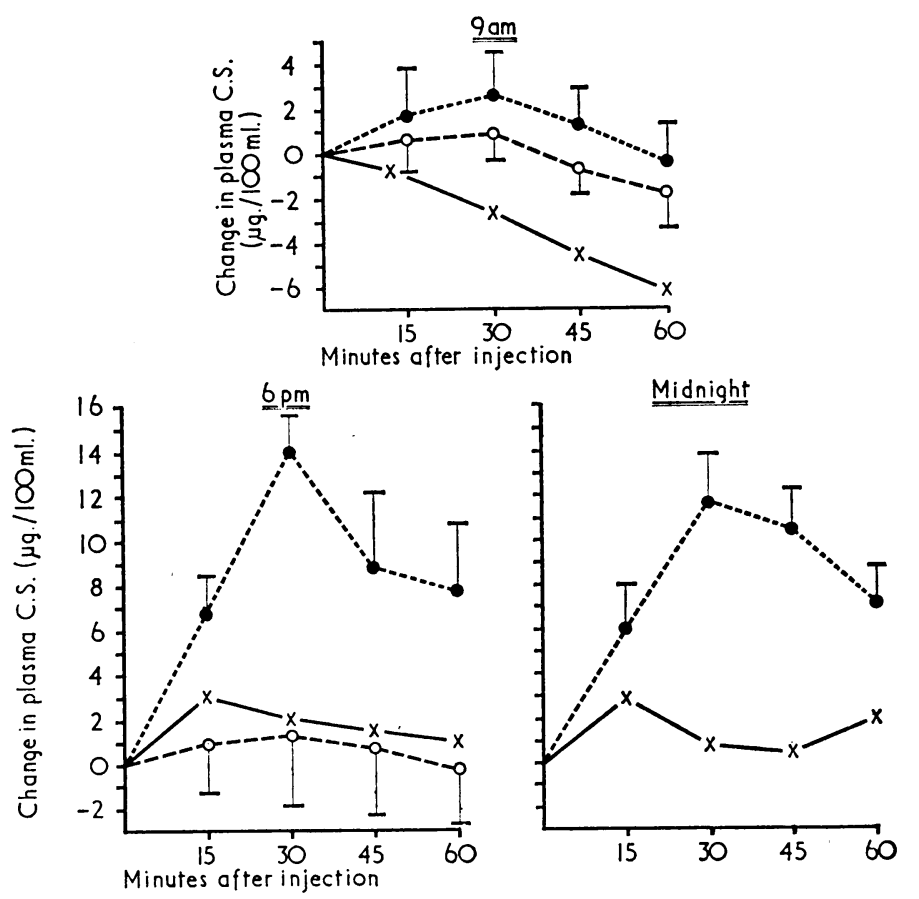

FIG. 2.-Changes in plasma fluorogenic corticosteroids (plasma CS.) after intravenous methylamphetamine (15 $\mathrm{mg}$. -- - $7.5 \mathrm{mg} . \mathrm{O}---\mathrm{O})$ and a placebo $(\times-\times)$ given at 9 a.m., 6 p.m., and midnight. Vertica bars represent 1 S.E. of the difference between means of active asd placebo effects.

TABLE II.-Mean Increments in Plasma Growth Hormone (H.G.H.) Concentration After Intravenous Methylamphetamine and a Placebc

\begin{tabular}{|c|c|c|}
\hline $\begin{array}{l}\text { Dose of } \\
\text { Methylamphetamine }\end{array}$ & $\begin{array}{l}\text { Mean } \\
\text { Maximum Increment } \\
( \pm 1 \text { S.E.) in H.G.H. } \\
\text { (ng./ml.) }\end{array}$ & $\begin{array}{c}\text { Mean difference }( \pm 1 \text { S.E.) } \\
\text { between Active and } \\
\text { Placebo Effects } \\
\text { (ng./ml.) }\end{array}$ \\
\hline $\begin{array}{l}15 \mathrm{mg} \text {. } \\
7.5 \mathrm{mg} \text {. } \\
\text { Placebo }\end{array}$ & $\begin{array}{l}9.8(2.9) \\
4.7(2.1) \\
1.3(0.9)\end{array}$ & $\begin{array}{l}8 \cdot 5(3 \cdot 1)^{*} \\
3 \cdot 4(1 \cdot 8) \\
\end{array}$ \\
\hline
\end{tabular}

The increase in growth hormone after $15 \mathrm{mg}$. of methylamphetamine was significant, whereas that after $7.5 \mathrm{mg}$. was not. Individual responses showed that a rise in growth hormone of $5 \mathrm{ng} . / \mathrm{ml}$. or more occurred on only 2 of the 12 occasions when a placebo was given, but such a rise occurred six times after the $7 \cdot 5$ - $\mathrm{mg}$. dose and nine times after $15 \mathrm{mg}$.

Circulating immunoreactive A.C.T.H. and fluorogenic corticosteroid levels after the intravenous administration of $15 \mathrm{mg}$. of methylamphetamine at $9 \mathrm{a} . \mathrm{m}$. to the additional two normal subjects are shown in Table III. There was a rise in immunoreactive A.C.T.H. which slightly preceded the corticcsteroid response.

TABLE III.-Plasma Fluorogenic Corticosteroid ( $\mu \mathrm{g} . / 100 \mathrm{mil}$ ) and Immunoreactive A.C.T.H. (pg./ml.) Levels After the Intraicnous Injection of Methylamphetamine (15 mg.) at 9 a.m.

\begin{tabular}{|c|c|c|c|c|c|c|c|}
\hline & & \multicolumn{6}{|c|}{ Minutes after Injection } \\
\hline & & 0 & 10 & 20 & 30 & 45 & 00 \\
\hline $\begin{array}{l}\text { Subject 1: } \\
\text { A.C.T.H. } \\
\text { Corticosteroids }\end{array}$ & $\therefore$ & $\begin{array}{l}40 \\
15\end{array}$ & $\begin{array}{l}60 \\
18\end{array}$ & $\begin{array}{r}160 \\
21\end{array}$ & $\begin{array}{l}80 \\
21\end{array}$ & $\begin{array}{l}65 \\
18\end{array}$ & $\begin{array}{l}50 \\
16\end{array}$ \\
\hline $\begin{array}{l}\text { Subiect 2: } \\
\text { A.C.T.H. } \\
\text { Corticosteroids }\end{array}$ & $\therefore$ & $\begin{array}{l}30 \\
14\end{array}$ & $\begin{array}{l}40 \\
14\end{array}$ & $\begin{array}{l}90 \\
19\end{array}$ & $\begin{array}{r}120 \\
20\end{array}$ & $\overline{19}$ & $\begin{array}{l}55 \\
19\end{array}$ \\
\hline
\end{tabular}




\section{Discussion}

The present study has shown that administration of the centrally stimulating sympathomimetic drugs dexamphetamine and methylamphetamine was associated with a rise in plasma fluorogenic corticosteroid levels. This effect was more pronounced in the evening than in the morning. Since the intravenous injection of methylamphetamine also caused a rise in circulating immunoreactive A.C.T.H. and growth hormone it is probable that the response is mediated via the anterior pituitary. The known occurrence of spontaneous bursts of growth hormone secretion in normal subjects may account for the rise which occurred in occasional subjects after the placebo. This, together with the small dose used, might explain why the growth hormone response to oral dexamphetamine was not significant. Psychometric tests showed that the rise in plasma fluorogenic corticosteroids after oral dexamphetamine was accompanied by evidence of mild generalized central stimulation.

Various explanations for these findings may be considered. The hypothalamic-pituitary-adrenal axis is stimulated in a wide variety of both physically and psychologically stressful situations, as is growth hormone secretion. It is therefore possible that the increased hormone levels demonstrated in the present study merely reflect the generalized and non-specific central stimulation. Naumenko (1967), however, reported that pipradrol, which caused more central stimulation than did amphetamine, did not raise plasma 17-hydroxycorticosteroids In guinea-pigs. On the other hand, Ohler and Wakerlin (1951) claimed that hydroxyamphetamine, which causes virtually no central stimulation, produced profound adrenal ascorbic acid depletion in rats. Thus when hypothalamic-pituitary-adrenal stimulation occurs after sympathomimetics it does not appear to be related to the degree of generalized central stimulation which they produce.

Many of the peripheral sympathomimetic effects of amphetamines are prevented by pretreatment with reserpine and are due to catecholamine release from adrenergic neurones. Naumenko (1967) suggested that amphetamine might stimulate the hypothalamus indirectly via this peripheral action. Against this hypothesis is the failure to demonstrate stimulation of the hypothalamic-pituitary-adrenal axis after exogenous adrenaline or noradrenaline (Tyler et al., 1955). In addition, the blood-brain barrier has been shown to be impermeable to catecholamines (Vogt, 1965), though it has been suggested that this may not be so in the hypothalamic region.

Adrenergic neurones are present within the hypothalamus (Shute and Lewis, 1966), and thus amphetamines, which readily cross the blood-brain barrier, might cause the local release of catecholamines, which may then, as suggested by Blackard and Heidingsfelder (1968), play a part in mediating the secretion of various pituitary-hormone-releasing factors. Since, however, the central stimulant actions of the amphetamines may not be prevented by pretreatment with reserpine (Innes and Nickerson, 1965), a more direct action of these drugs, independent of catecholamine release, on hypothalamic or mid-brain receptors cannot be excluded as an explanation for the hormone changes observed. Studies of growth hormone and corticosteroid responses to amphetamines during alpha- and beta-blockade are now in progress to explore these possibilities further.

There is now extensive evidence indicating that midbrain structures continuously exert an inhibitory influence on corticotrophin-releasing factor and therefore on A.C.T.H. release (Slusher, 1966). Indeed, it is possible that the normal nyctohemeral rhythm of pituitary-adrenal function reflects changes in the degree of reticular inhibition, with the decrease in circulating corticosteroid levels seen in the evening being due to an increased degree of inhibition. Amphetamine has stimulant actions on the reticular formation, and it is of interest, therefore, that dexamphetamine impairs the normal nyctohemeral rhythm (Butler et al., 1968), and, as shown in the present study, amphetamines have an enhanced effect when given during the late evening, when reticular inhibition is presumed to be greatest. Thus the effects of amphetamines on plasma corticosteroids might be a result of the abolition of inhibitory impulses from the midbrain. Though the maximum corticosteroid levels seen at 9 a.m. and 6 p.m. were not significantly different, those at midnight were lower, and hence, if this explanation is correct, it would appear that the dose of methylamphetamine used was sufficient to counter, in full, the inhibition operating at 9 a.m. and 6 p.m., but could only partially overcome the greater degree of inhibition present at midnight.

Work is in progress to investigate further the relation between centrally acting drugs, central stimulation, and endocrine function in man. It is hoped that this may help to clarify the mechanisms involved in the control of hypothalamic and pituitary activity, and such studies might serve as the basis for establishing a simple and safe test of pituitary-adrenal function.

We gratefully acknowledge the interest and advice of Professor E. F. Scowen, Professor F. C. Greenwood, and Dr. Hannah Steinberg. We also thank Mrs. C. Bristow, Mrs. C. Gosling, and Mrs. J. Heath for skilled technical assistance, and the Robert McAlpine Foundation and Ciba Laboratories for generous financial support.

\section{REFERENCES}

Besser, G. M., and Steinberg, H. (1967). Thérapie, 22, 977.

Blackard, W. G., and Heidingsfelder, S. A. (1968). Fournal of Clinical Investigation, 47, 1407.

Butler, P. W. P., Besser, G. M., and Steinberg, H. (1968). Fournal of Endocrinology, 40, 391.

Dickens, D. W., Lader, M. H., and Steinberg, H. (1965). British fournal of Pharmacology, 24, 14.

Hunter, W. M., and Greenwood, F. C. (1964). Biochemical fournal, 91, 43.

Innes, I. R., and Nickerson, M. (1965). In The Pharmacological Basis of Therapeutics, 3rd ed., p. 502, edited by L. S. Goodman and A. Gillman. New York, MacMillan.

Klein, R., and Livingston, S. (1950). Fournal of Paediatrics, 37, 733.

Korányi, L., Endröczi, E., and Tárnck, F. (1966). Neuroendocrinology, 1,144 .

Kornetsky, C., and Humphries, O. (1958). Fournal of Mental Science, 104, 1093 .

Landon, J., and Greenwood, F. C. (1968). Lancet, 1, 273.

Mattingly, D. (1962). Fournal of Clinical Pathology, 15, 374.

Mess, B., and Martini, L. (1968). In Recent Advances in Endocrinology, edited by V. H. T. James, p. 1. London, Churchill.

Müller, E. E., Saito, T., Arimura, A., and Schally, A. V. (1967). Endocrinology, 80, 109.

Murphy, J. V., and Miller, R. E. (1955). Fournal of Comparative and Physiological Psychology, 48, 47.

Naumenko, E. V. (1967). Endocrinology, 80, 69.

Nasmyth, P. A. (1949). Fournal of Physiology, 110, 294.

Ohler, E. A., and Wakerlin, G. E. (1951). Fournal of Laboratory and Clinical Medicine, 38, 935.

Shute, C. C. D., and Lewis, P. R. (1966). British Medical Bulletin, 22, 221.

Silverstone, J. T., and Stunkard, A. J. (1968). British Foumal of Pharmacology and Chemotherapy, 33, 513.

Slusher, M. A. (1966). Experimental Brain Research, 1, 184.

Tyler, F. H., Migeon, C., and Castle, H. (1955). Colloquia on Endocrinology, 8, 254 .

Vogt, M. (1965). British Medical Bulletin, 21, 57.

Weiss, B., and Laties, V. G. (1962). Pharmacological Reviews, 14, 1. 